University of Nebraska - Lincoln

DigitalCommons@University of Nebraska - Lincoln

Faculty Publications, Department of Psychology

Psychology, Department of

2019

Posttraumatic Stress and Parenting Behaviors: The Mediating

Role of Emotion Regulation

\author{
Shaina A. Kumar \\ University of Nebraska-Lincoln, skumar@huskers.unl.edu \\ Molly R. Franz \\ VA Boston Healthcare System \\ Rebecca L. Brock \\ University of Nebraska-Lincoln, rebecca.brock@unl.edu \\ David DiLillo \\ University of Nebraska-Lincoln, ddilillo@unl.edu
}

Follow this and additional works at: https://digitalcommons.unl.edu/psychfacpub

Part of the Psychology Commons

Kumar, Shaina A.; Franz, Molly R.; Brock, Rebecca L.; and DiLillo, David, "Posttraumatic Stress and Parenting Behaviors: The Mediating Role of Emotion Regulation" (2019). Faculty Publications, Department of Psychology. 961.

https://digitalcommons.unl.edu/psychfacpub/961

This Article is brought to you for free and open access by the Psychology, Department of at DigitalCommons@University of Nebraska - Lincoln. It has been accepted for inclusion in Faculty Publications, Department of Psychology by an authorized administrator of DigitalCommons@University of Nebraska - Lincoln. 


\title{
Posttraumatic Stress and Parenting Behaviors: The Mediating Role of Emotion Regulation
}

\author{
Shaina A. Kumar, ${ }^{1}$ Molly R. Franz,, ${ }^{1,2}$ \\ Rebecca L. Brock, ${ }^{1} \&$ David DiLillo ${ }^{1}$ \\ 1 Psychology Department, University of Nebraska-Lincoln, 238 Burnett Hall, \\ Lincoln, NE 68588-0308, USA \\ 2 Molly R. Franz is currently affiliated with the National Center for PTSD at the VA \\ Boston Healthcare System and Boston University School of Medicine.
}

Corresponding author - Molly R. Franz mfranz@bu.edu

\begin{abstract}
Maternal trauma has been linked with problematic parenting, including both harsh and permissive behaviors. However, little is known about mechanisms accounting for this association. The current study examined the potential impact of posttraumatic stress disorder (PTSD) and emotion regulation on dysfunctional parenting behaviors in a sample of community mothers. We hypothesized a mediation model wherein PTSD would be associated with dysfunctional parenting (i.e., lax and overreactive behaviors) indirectly through deficits in maternal emotion regulation. Seventy-eight community mothers of 18- to 36-month-old children were administered the Clinician Administered PTSD Scale for DSM-5 (CAPS-5) and 19 mothers met criteria for PTSD. Mothers also completed self-report measures of difficulties with emotion regulation and maternal laxness and overreactivity in parenting. Results revealed that emotion dysregulation fully mediated relations between PTSD status and lax (but not overreactive) parenting behaviors. Compared to mothers without PTSD, those with PTSD reported greater lax parenting behaviors indirectly through greater emotion dysregulation. Mothers with PTSD may struggle to parent assertively when trauma symptoms interfere with emotion regulation abilities. The current study highlights the need to design interventions focused on helping trauma-exposed mothers manage distress, ultimately aiming to enhance parenting effectiveness and improve child outcomes.
\end{abstract}

Published in Journal of Family Violence, 2019

DOI: 10.1007/s10896-019-00124-5

Copyright (C) 2019 Springer Science+Business Media, LLC, part of Springer Nature.

Used by permission.

Published 19 December 2019. 
Keywords: Emotion regulation, Family, Lax, Mothers, Permissive, Parenting, Posttraumatic stress disorder, Trauma

\section{Introduction}

Although a greater proportion of men than women experience traumatic events ( $61 \%$ versus $51 \%$, respectively), the lifetime rate of PTSD is approximately twice as high among women (10\% of women compared to $5 \%$ of men; Kessler et al. 1995). Moreover, data from the National Comorbidity Study show that nearly three-quarters of individuals meeting criteria for PTSD are mothers (Nicholson et al. 2002). This figure is concerning, in part, because of the potential systemic impact of PTSD that can extend to survivors' interpersonal relationships (e.g., Monson et al. 2010), which include impaired parent-child interactions among adults with PTSD (e.g., Creech and Misca 2017; DiLillo and Damashek 2003; Leen-Feldner et al. 2011). However, relatively little research has examined factors that may mediate relations between maternal PTSD and parenting difficulties. The present study addresses this gap by examining the possible impact of PTSD on mothers' discipline strategies with young children and investigating emotion dysregulation as a mechanism that may account for this association.

\section{Emotion Regulation and Parenting}

Child noncompliance is a normative aspect of toddlerhood, emerging as children begin to assert greater agency and autonomy (Kuczynski and Kochanska 1990), and necessitating parent competence in managing conflictual interactions. Dix's (1991) seminal model of parenting identifies three key components motivating parent competence, at the heart of which is emotion regulation. This model posits that (a) child behavior and contextual factors (e.g., high-stress, low-support environments) influence (b) parent emotion regulation, which in turn (c) motivates parents to engage in certain parenting behaviors. Interactions in which parents must manage child behavior they experience as aversive often evoke negative parental emotions (Dix 1991; Lorber 2007), and difficulties regulating these emotions may increase or inhibit particular parenting strategies (Dix 1991; Lorber and Slep 2005). Responding effectively to instances of noncompliance requires parents to manage their own feelings and reactions to prioritize their child's wellbeing (e.g., calmly redirecting a child 
instead of yelling). In the absence of effective emotion regulatory skills, maladaptive parenting responses make take different forms. Maternal emotion dysregulation may lead to lax discipline behaviors due to mothers feeling the need to distance from their own emotions and avoid challenging child behaviors; alternatively, emotion dysregulation may lead to harsh discipline behaviors due to mothers feeling emotionally overwhelmed and thus responding to their child's behavior in a hostile manner to gain quick compliance.

Effective emotion regulation is a prerequisite to adaptive parenting responses to child misbehavior (e.g., Deater-Deckard et al. 2010; Lorber 2012). Recent reviews document linkages between effective emotion regulation and positive parenting (e.g., Crandall et al. 2015; Crandall et al. 2016; Zalewski et al. 2018). Behaviors that emphasize support and consistent instruction are indicative of good parental emotion regulation (Crandall et al. 2015) and associated with positive child behavior and adjustment (Amato and Fowler 2002). In contrast, parenting behaviors that communicate harshness or permissiveness (e.g., displays of anger or irritation, allowing rules to go unenforced; Arnold et al. 1993) can heighten child noncompliance in ways that persist and evolve into aggression and destructiveness over time (Campbell et al. 2000).

\section{PTSD and Emotion Dysregulation}

Aligned with Dix's (1991) view that factors giving rise to parent emotion dysregulation might undermine effective parenting, PTSD may pose unique challenges to parent competence through its influence on emotion dysregulation. PTSD is characterized by a persistent sense of current threat that results in experiential, emotional, and behavioral avoidance, as individuals attempt to limit their own exposure to emotionally evocative cues (Foa and Rothbaum 1998). However, these avoidance patterns are associated with a paradoxical increase in emotional distress (Hayes et al. 1996), as well as greater unpredictability of mood states (Kashdan et al. 2006; Orsillo et al. 2004), lower distress tolerance (e.g., Vujanovic et al. 2011), and more intense emotional and physiological responses to negative stimuli (e.g., McDonagh-Coyle et al. 2001; Veazey et al. 2004). Thus, mothers with PTSD may struggle to identify, tolerate, and respond to intense emotional arousal in ways needed to manage child misbehavior. 


\section{PTSD and Parenting}

Consistent with the above possibilities, survey and observational data reveal positive relations between PTSD symptom severity and dysfunctional parenting behaviors (e.g., Ammerman et al. 2012; Hershkowitz et al. 2017; Leen-Feldner et al. 2011; van Ee et al. 2012). For example, researchers found a positive association between parental PTSD and moderate physical aggression toward children after accounting for socioeconomic status and other psychopathology (Leen-Feldner et al. 2011). Similarly, observations of interactions between asylum seekers and their children reveal positive associations between PTSD severity and insensitive, unstructured, and hostile parenting behaviors during free play (van Ee et al. 2012). Although several studies suggest that mothers exposed to trauma, including those who do not go on to develop significant psychopathology, may compensate for the potential effects of trauma by increasing positive parenting behaviors (e.g., Casanueva et al. 2008; Letourneau et al. 2007; Levendosky et al. 2000, 2003), most literature points to PTSD as having a detrimental impact on parent-child relations (see Creech and Misca 2017; van Ee et al. 2015 for reviews).

Despite growing evidence linking PTSD to both parenting difficulties and emotion dysregulation (e.g., Orsillo et al. 2004; van Ee et al. 2012), as well as findings that emotion dysregulation undermines parenting behaviors (e.g., Lorber 2012), scant research has examined whether emotion dysregulation mediates the link between PTSD and parenting. The present study addresses this gap in knowledge as well as other limitations found in prior literature. Most studies to date focus on specific trauma-exposed populations (e.g., combat veterans, mothers exposed to intimate partner violence); less is known about whether community samples of mothers with diverse trauma experiences are similarly affected. Additionally, in most prior work, PTSD symptoms and potential diagnoses are inferred from responses to symptom checklists. However, diagnostic interviewing methods, considered the gold standard approach to assessing PTSD (Wisco et al. 2012), may facilitate more precise measurement of symptoms, and thus more accurate diagnoses. The present study addresses these limitations by utilizing a diagnostic interview to more rigorously assess PTSD in a community sample of mothers with diverse trauma experiences. 


\section{Aims and Hypotheses}

In sum, prior literature suggests PTSD may contribute to dysfunctional parenting behaviors among parents and emotion regulation associated with PTSD may be an important mechanism through which these parenting difficulties occur. The goal of the present study was to test these possibilities by examining emotion regulation as a mediator of the association between PTSD and maternal parenting behaviors. First, we expected that mothers meeting diagnostic criteria for PTSD would report more dysfunctional parenting, as exhibited by greater lax and harsh parenting behaviors. Second, drawing on prior theory and research, we predicted that higher levels of emotion dysregulation associated with a diagnosis of PTSD would be associated with increased levels of both harsh and lax parenting behaviors. Finally, we expected that poorer emotion regulation would mediate the relation between PTSD and both lax and harsh parenting behaviors.

\section{Method}

\section{Participants}

Participants were 78 adult mothers of toddler-aged children recruited from a medium-sized Midwestern city. Mothers ranged in age from 21 to 45 years $(M=32.98 ; S D=5 \cdot 37)$. The majority of mothers identified as White $(n=71 ; 91 \%)$, while $6 \%(n=5)$ identified as multiracial and $3 \%$ $(n=2)$ identified as Asian. Approximately 6\% $(n=5)$ of mothers identified as Hispanic/Latina. Taken together, $15 \%(n=12)$ of mothers identified with either a racial or ethnic minority group. Most mothers were married ( $n=61 ; 78 \%)$ or currently in a romantic relationship $(13 \% ; n=10)$. The majority were employed $(n=60 ; 77 \%)$, and $47 \%(n=37)$ reported having a bachelor's degree. The modal combined family income was over $\$ 100$, ooo $(n=18)$, but ranged with approximately $47 \%(n=37)$ of the sample earning at or below an income of $\$ 60,000$. 


\section{Procedures}

\section{Recruitment}

Participants were part of a larger study examining the impact of PTSD on parenting among mothers and their 18- to 36-month-old children. Recruitment of mother-child dyads for the larger study occurred primarily through archived birth announcements published in the local newspaper. These birth announcements are provided to the newspaper by each hospital in the county and therefore reflect all the hospital births of children from the recruitment area. Using publically available contact information for parents listed in the birth announcements, potential participants were mailed letters inviting them to participate in a study of "parent-child interactions." A total of 52 mothers were recruited via their children's birth announcements; 16 mothers were recruited via flyers posted in daycares, community centers, grocery stores, and libraries; and remaining mothers were recruited via word of mouth $(n=4)$, university websites and listservs $(n=3)$, and Craigslist advertisements $(n=3)$. Mothers received $\$ 10$ compensation after completing the 30-minute online survey and \$15 per hour during the lab portion of the study.

\section{Initial Screening and Data Collection}

Mothers who responded to recruitment letters or advertisements were asked complete an online version of the Life Events Checklist for DSM-5 (LEC-5; Weathers et al. 2013a) followed by the PTSD Checklist for DSM-5 (PCL-5; Blevins et al. 2015). Oversampling was used during recruitment to ensure a sufficient number of participants had experienced trauma and PTSD. Eligible mothers were scheduled for a single lab visit. Upon arrival, mothers underwent informed consent procedures and then completed a demographics questionnaire, the CAPS- 5 interview, measures of parenting and emotion dysregulation, and a series of additional tasks relevant to the larger study from which these data were drawn. Pregnant women were excluded from participation due to alterations in cortisol hormones occurring during pregnancy (Nolten et al. 1980), a variable relevant to the larger study. Steps were taken to minimize risk, including carefully obtaining informed consent, offering all participants referral information for trauma-specific treatment, and providing thorough debriefing about the purposes of the study. The university's Institutional Review Board approved all study methods. 


\section{Measures}

\section{Demographics}

Mothers completed a demographics survey including questions about their age, race, ethnicity, total yearly household income, and highest level of education.

\section{PTSD Classification}

Mothers who reported a Criterion A trauma on the LEC-5 (Weathers et al. 2013a) were administered the Clinician-Administered PTSD Scale for DSM-5 (CAPS-5; Weathers et al. 2013b). The CAPS-5 was used for the final classification of participants into PTSD or no PTSD groups. The CAPS-5 produces a current (past month) diagnosis, symptom cluster severity, and overall symptom severity. The measure has strong interrater reliability ( $\kappa=.78$ to 1.00 depending on scoring rule) and good test-retest reliability (ICC $=.78$ ), as well as strong convergent validity with related measures (e.g., CAPS-IV, PCL-5, anxiety, functional impairment; Weathers et al. 2017).

\section{Self-Reported Parenting Behaviors}

To examine overreactive and lax parenting behaviors, mothers completed the Parenting Scale (Arnold et al. 1993). The Parenting Scale is a self-report measure in which parents rate their tendencies to engage in overreactive (10 items), lax (11 items), and verbose ( 7 items) discipline techniques. The overreactive and lax discipline subscales were examined for the purpose of the current study. Overreactive styles reflect the frequency of responding to child misbehavior in a hostile manner either verbally (e.g., yelling) or physically (e.g., grabbing an arm), while lax styles reflect the frequency of "giving in" to child misbehavior. Sample items from these scales include, "If my child gets upset, I back down and give in," and "I raise my voice or yell," for lax and overreactive discipline, respectively. Responses are coded on a 7-point Likert format scale (i.e., $1=$ frequent use of effective discipline strategies to $7=$ frequent use of discipline mistakes) and yield a continuous score. Research indicates convergent validity between discipline behaviors in both observed and self-report measures of overreactive $(r=.61)$ and lax parenting behaviors $(r=.65$; Arnold et al. 1993), as well as high interrater reliability ( $r$ s ranging from 
.86 to .91; Arnold and O'Leary 1995). In the current study, mean overreactive parenting was $24.96(S D=7.28$; range $10-70)$ and mean lax parenting was $28.73(S D=9.14$; range 11-77). The alpha coefficients across both scales were respectable (overreactive discipline $\alpha=.79$; lax discipline $\alpha=.82$ ).

\section{Emotion Regulation}

To assess emotion regulation, mothers completed the Difficulties in Emotion Regulation Scale (DERS; Gratz and Roemer 2004). The DERS is a 36-item self-report questionnaire that measures overall emotion regulation, as well as six specific subscales (i.e., non-acceptance of emotional responses, difficulty engaging in goal-directed behavior, impulse control difficulties, lack of emotional awareness, limited access to emotion regulation strategies, lack of emotional clarity). Sample items include, "When I'm upset, I lose control over my behavior," and "When I'm upset, I have difficulty thinking about anything else." Responses are coded on a 5-point Likert format scale (i.e., $1=$ almost never to $5=$ almost always) and yield a continuous score. Research indicates adequate construct and predictive validity of the DERS (Gratz and Roemer 2004). For the purpose of the current study, items were summed across subscales and internal consistency was respectable $(\alpha=.85)$.

\section{Child Behavior Problems}

Child internalizing and externalizing symptoms were assessed with the Child Behavior Checklist for Ages 1.5 to 5 (CBCL; Achenbach and Rescorla 2000). Items were summed to create a total score and internal consistency was high $(\alpha=.92)$. The CBCL total score was included as a covariate in analyses.

\section{Data Analytic Plan}

\section{Power Considerations}

Statistical power for testing the models relevant to the larger study from which these data were drawn was estimated a priori using a Monte Carlo simulation (Muthén and Muthén 1998-2017; Thoemmes et al. 2010). These results indicated that 75 mother-child dyads would be sufficient for testing each of the proposed models, assuming medium effect sizes and power $>.80$ ). Although statistical power was not estimated a priori for these secondary data analyses, it is worth noting that the larger study 
aimed to test more complex models (i.e., a model with two predictors and two mediators), suggesting that the sample size is more than adequate for the present investigation.

\section{Data Screening}

Screening of the data revealed normal distributions and no missing data on any primary variables of interest. Frequencies and means were calculated for sample demographics, followed by bivariate correlations, which were conducted to determine associations among constructs of interest and identify potentially important covariates. Several demographic variables (i.e., maternal age, minority status, household income, educational attainment) and child characteristics (i.e., child age, child sex) were examined, but only household income and mother's education level were identified for inclusion as covariates by virtue of their significant associations with PTSD status and emotion regulation. Specifically, mothers with lower household incomes were more likely to have PTSD $(r=-0.39, p=$ .001) and report poorer emotion regulation $(r=-0.32, p=.004)$. Additionally, mothers with lower educational attainment were more likely to report poorer emotion regulation $(r=-0.29, p=.011)$. Child behavior problems (internalizing and externalizing symptoms assessed with the CBCL; Achenbach and Rescorla 2000) were also associated with poorer maternal emotion regulation $(r=0.38, p=.001)$, as well as maternal overreactivity ( $r=0.36, p=.001)$, and therefore was statistically controlled to account for differences in parenting attributable to child effects. We adjusted for these covariates by regressing our outcome variables (maternal laxness, overreactivity), as well as our mediator (maternal emotion regulation), on household income, educational attainment, and child behavior problems.

\section{Hypothesis Testing}

Next, using Mplus 8.1 (Muthén and Muthén 1998-2017), we tested our primary hypotheses focusing on the direct and indirect effects of PTSD on maternal parenting behaviors (i.e., laxness and overreactivity) as mediated though emotion dysregulation. Here, we employed Hayes' (2017) mediation criteria such that the inference of indirect effects should be based on the product of paths $a$ and $b$ (i.e., $a b$ ), as opposed to the individual hypothesis tests of $a$ and $b$ separately. Because the product of $a b$ can be significantly different from zero even when $a$ and $b$ are not statistically significant, statistical significance of both $a$ and $b$ as separate entities are not 
requirements of mediation (Hayes 2017, p. 116). Through this approach, a bias-corrected bootstrap technique with 5000 resamples was used to derive the $95 \%$ CIs for direct and indirect effects. This non-parametric resampling method accounts for non-normal distribution of indirect effects and performs well in small samples by maximizing power while minimizing Type 1 error rate (Shrout and Bolger 2002). Based on the number of paths, the model was just-identified (i.e., zero degrees of freedom). As global fit indices do not apply to just-identified models, only local fit indices are reported.

\section{Results}

\section{Preliminary Analyses}

Recruitment efforts resulted in a final sample of 19 mothers meeting criteria for PTSD and 59 who did not meet criteria for PTSD. Participants with PTSD identified a range of events on the LEC-5 as their "worst" index trauma, including physical and/or sexual domestic violence $(n=5$; $26.3 \%)$, physical and/or sexual child abuse ( $n=4 ; 21.1 \%)$, sexual assault by a stranger or friend ( $n=2 ; 10.5 \%)$, transportation accident $(n=1$; $5 \cdot 3 \%)$, kidnapping/captivity $(n=1 ; 5 \cdot 3 \%)$, exposure to a war-zone ( $n=$ $1 ; 5.3 \%)$, experiencing life-threatening illness/injury ( $n=1 ; 5 \cdot 3 \%)$, witnessing a life threatening illness/injury $(n=2 ; 10.5 \%)$, learning about a loved one's sexual assault ( $n=1 ; 5.3 \%$ ), and learning about a sudden violent death $(n=1 ; 5 \cdot 3 \%)$. Participants with PTSD received an average severity score of $31.95(S D=8.95)$.

\section{Bivariate Relations}

Bivariate correlations were estimated using Pearson's formula. As expected, PTSD status significantly correlated with greater emotion dysregulation $(r=.29, p<.01)$. Greater emotion dysregulation significantly correlated with greater maternal laxness $(r=.38, p<.01)$, as well as greater overreactivity $(r=.28, p<.05)$. Surprisingly, PTSD status was not significantly associated with either maternal laxness or overreactivity. All variables were sufficiently distinct $(r s<.70)$, and thus there were no concerns about multicollinearity (Tabachnick and Fidell 1996). 


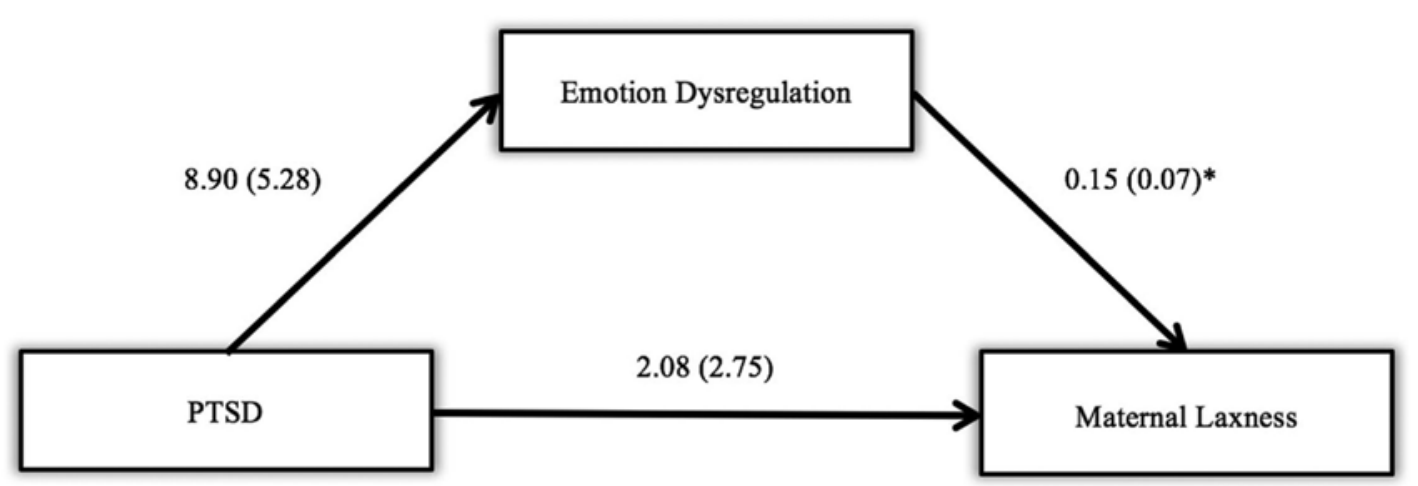

Fig. 1. Unstandardized regression coefficients (b) and standard errors (SE) in path model depicting the influence of PTSD diagnosis and emotion dysregulation on maternal laxness. PTSD status was significantly related to higher maternal laxness indirectly through greater emotion dysregulation, $\mathrm{b}=1.34, \mathrm{SE}=1.00,95 \% \mathrm{CI}[0.05,4.49]$. Estimates with asterisks are significant at $p<.05$

\section{Path Analyses}

\section{Lax Parenting}

As shown in Fig. 1, among mothers with PTSD, compared to those without PTSD, results indicated a nonsignificant direct path from PTSD status to maternal laxness, $b=2.08, S E=2.75,95 \%$ CI $[-3.44,7.35]$. PTSD status did not predict greater emotion dysregulation, $b=8.90, S E=5.28$, 95\% CI [-0.94, 19.50]; however, greater emotion dysregulation significantly predicted higher maternal laxness, $b=0.15, S E=0.07,95 \% \mathrm{CI}$ [0.03, 0.29]. Further, PTSD status was significantly related to higher maternal laxness indirectly through greater emotion dysregulation, $b=1.34$, $S E=1.00,95 \%$ CI $[0.05,4.49]$, thus meeting criteria for mediation. Regarding the covariates, child behavior problems was significantly associated with greater emotion dysregulation, $b=0.35, S E=0.15,95 \% \mathrm{CI}$ [0.08, 0.66]. The model accounted for $21 \%$ of the variance in emotion dysregulation and $16 \%$ of the variance in lax parenting.

\section{Overreactive Parenting}

Among mothers with PTSD, results indicated a nonsignificant direct path from PTSD status to maternal overreactivity, $b=-1.39, S E=2.42$, 95\% CI $[-5.77,3.77]$. PTSD status did not predict greater emotion dysregulation, $b=8.89, S E=5.28$, 95\% CI [-0.96, 17.78], and greater emotion dysregulation did not significantly predict higher maternal overreactivity, 
$b=0.07, S E=.04,95 \%$ CI $[-0.01,0.16]$. Further, PTSD status was not significantly related to maternal overreactivity indirectly through emotion dysregulation, $b=0.58, S E=0.56$, 95\% CI [-0.51, 2.41], thus not meeting criteria for mediation. Regarding the covariates, child behavior problems was significantly associated with greater emotion dysregulation, $b$ $=0.35, S E=0.15,95 \%$ CI [0.08, 0.66], and greater overreactive parenting behaviors, $b=0.12, S E=0.06,95 \% \mathrm{CI}[0.00,0.25]$.

\section{Discussion}

The goal of this study was to examine whether PTSD predicted maternal parenting behaviors, as well as the possible role of emotion dysregulation in explaining this association. Contrary to expectations, there was no direct association between PTSD status and self-reported dysfunctional parenting behaviors. However, results revealed an indirect effect of maternal PTSD on lax (but not overreactive) parenting behaviors through greater emotion dysregulation. We discuss the implications of these findings below.

\section{PTSD and Dysfunctional Parenting}

Our finding that PTSD status was not directly associated with either lax or overreactive parenting contrasts with prior work linking PTSD to negative parenting outcomes (e.g., Leen-Feldner et al. 2011; van Ee et al. 2012). Nevertheless, other literature suggests that mothers exposed to trauma may compensate for the adverse impact of these events by increasing their focus on effective parenting behaviors, such as positive discipline, sensitivity, and consistency (e.g., Casanueva et al. 2008; Letourneau et al. 2007; Levendosky et al. 2000). Some of the trauma-exposed mothers in the present study may have similarly tried to offset the systemic impact of their trauma history through increased focus on positive parenting behaviors. Our sample was also characterized by a relatively high level of socioeconomic status and education, both of which may serve as protective factors against parenting difficulties (e.g., Neitzel and Dopkins Stright 2004; Pinderhughes et al. 2000), even among mothers with PTSD. For example, these mothers may have access to resources (e.g., counseling services, social support from family and friends) that could buffer the potential impact of PTSD on their parenting behaviors-a possibility supported by findings that better access to resources is associated with more 
effective parenting practices (Kotchick and Forehand 2002). Alternatively, mothers concerned with impression management may have underreported negative behaviors on the self-report parenting measure used here (i.e., social desirability effects). If mothers internalized societal pressures and attempted to depict themselves in an idealized fashion, this could have resulted in the minimizing of parenting difficulties (see Morsbach and Prinz 2006; Schaeffer 2000 for discussions).

\section{PTSD, Emotion Regulation, and Lax Parenting}

As predicted, greater emotion dysregulation mediated associations between PTSD status and greater lax parenting. Results are consistent with prior work linking PTSD to greater emotion dysregulation (e.g., Orsillo et al. 2004; McDonagh-Coyle et al. 2001; Veazey et al. 2004), and complements a recent study of mothers of older children, which found that emotion dysregulation mediated the association between PTSD and supportive parenting reactions (Gurtovenko and Katz 2017). However, multiple prior studies of community samples (without regard to trauma history) have not found support for the link between parental negative emotion and permissive parenting behaviors, concluding that maternal emotion regulation may be less relevant for lax discipline (Leung and Slep 2006; Lorber and Slep 2005; Lorber 2012). The present findings align more with early research linking maternal trauma to permissive parenting, possibly as a result of mothers having diminished emotional resources to enforce discipline or communicate consistent behavioral expectations to their children (see DiLillo and Damashek 2003 for a discussion). In particular, the avoidance and emotional numbing component of PTSD may have a deleterious effect on the parent-child relationship (Samper et al. 2004). Together with present findings, work in this area suggests that PTSD may increase mothers' tendency to avoid managing child misbehavior when greater levels of emotion regulation are needed for effective, approachoriented discipline.

\section{PTSD, Emotion Regulation, and Overreactive Parenting}

The lack of mediation between PTSD and overreactive parenting through emotion regulation was unexpected in light of prior work linking (a) PTSD to greater emotion dysregulation during emotionally evocative situations (e.g., McDonagh-Coyle et al. 2001; Veazey et al. 2004) and (b) poor emotion regulation to harsh parenting (e.g., Lorber 2012). We did, however, find the expected bivariate associations between PTSD 
status and emotion dysregulation and between emotion dysregulation and both overreactive and lax parenting. Although PTSD status was not significantly associated with either maternal laxness or overreactivity, the strength of the correlation between PTSD and laxness $(r=.21, p=.06)$ was substantially higher than that of PTSD and overreactivity $(r=.04, p=$ .70). Moreover, some items on the Parenting Scale clearly reflect face-valid dysfunctional parenting practices (e.g., "When my child does something I don't like, I insult my child, say mean things, or call my child names”), which may lead to underreporting of these behaviors due to social desirability bias. Future research could reduce these biases by using observational methods in which researchers measure actual parenting behaviors during routine discipline encounters.

\section{Limitations}

Although the current study contributes to prior knowledge about PTSD and parenting, its findings should be viewed in light of several limitations. First, the cross-sectional design precludes conclusions about causation and the temporal order of variables in our model. Further examination of PTSD, emotion regulation, and parenting outcomes in the context of a longitudinal study are needed to address these issues. Second, our sample was relatively small, ethnically homogenous, of higher socioeconomic status, and well-educated. It is possible that individuals from varying racial/ethnic and socioeconomic groups may experience PTSD and emotion regulation to differing degrees due to reduced access to mental health care and increased exposure to daily stressors (Myers 2009; Santiago et al. 2011). Mothers in the current sample may have more resources at their disposal, whereas mothers from disadvantaged backgrounds may lack access to myriad types of support (e.g., community networks, financial resources, educational environments; Kotchick and Forehand 2002). Research has long documented associations between economic strain and increased behavioral problems among children via greater caregiver negative emotionality and harsher discipline practices among parents (see Evans 2004 for a review). Future research should include a more demographically diverse sample to facilitate broader generalization of findings. In addition to the possible underreporting of parenting difficulties noted earlier, mothers who have difficulty regulating their emotions may also struggle to accurately report upon certain facets of emotion regulation. For example, individuals who have difficulty identifying their own affective 
states may misrepresent the intensity and frequency of their emotions on self-report questionnaires (Gratz and Roemer 2004). Using observational or interview methods to more comprehensively assess emotion regulation and parenting behaviors may address this issue.

\section{Future Directions}

Future research is needed to better understand the role of PTSD in parenting difficulties. Like most work in this area, the current study focused on mothers; however, fathers are underrepresented in the parenting literature (e.g., Davison et al. 2017; Phares et al. 2005), and research indicates that men with PTSD also experience parenting difficulties (Stover et al. 2012). More work is needed to fully understand the nature of parenting difficulties experienced by fathers and to identify the mechanisms underlying this relation. Second, our a priori hypotheses focused on global emotion regulation. However, emotional regulation can be conceptualized as a multidimensional construct involving the awareness, understanding, and acceptance of one's emotions; the ability to control impulsive behaviors and engage in goal-directed behaviors when upset; and the flexible use of strategies to manage the intensity and duration of emotions in responses to specific situations (Gratz and Roemer 2004). Thus, the present findings could be extended by examining specific facets of emotion regulation in relation to maternal PTSD and parenting behaviors. For example, mothers with impulse control difficulties may be more likely to struggle with managing overt displays of irritability (i.e., harsh parenting), whereas mothers with limited access to particular emotion regulation strategies might have difficulty modulating their distress in order to set limits on their children (i.e., lax parenting). Third, PTSD is likely to operate upon parenting via a variety of pathways and additional mechanisms may account for these associations. For instance, cross-sectional data suggest that parenting stress may mediate associations between PTSD and child outcomes (e.g., Samuelson et al. 2017). Certain trauma-related thoughts and beliefs (i.e., posttraumatic cognitions) are also known increase both PTSD symptoms (Foa et al. 1999; Mordeno et al. 2017) and parental distress (Tutus and Goldbeck 2016), and thus could be important constructs of interest. In particular, preoccupation with negative cognitions related to the self (e.g., "I am unlovable") may lead to ineffective parenting practices (i.e., permissive parenting) in an attempt to achieve greater closeness with one's child. Finally, future research should examine moderators 
of the association between PTSD and parenting, which may be critical to enhancing effective parenting among mothers with PTSD. To name a few possibilities, perceived social support, close alliance with a mental health professional, and psychological resilience are all factors known to buffer the harmful effects of trauma on functional impairment (e.g., Charuvastra and Cloitre 2008; Pietrzak et al. 2010).

\section{Clinical Implications and Conclusion}

The current study provides new information regarding the role that PTSD and emotion regulation might play in increasing problematic parenting behaviors among mothers and their toddler-aged children. Results suggest that mothers who have experienced a traumatic event resulting in PTSD may be at risk for problems with emotion regulation and, in turn, lax or permissive parenting behaviors. It is possible that permissive parenting reflects challenges in distress tolerance manifesting in difficulty withstanding the emotional distress associated with parenting (e.g., when needing to set firm boundaries with misbehaving children). For this reason, interventions centered around improving emotion regulation skills and interpersonal effectiveness (e.g., Dialectical Behavior Therapy [DBT]; Linehan 1993a, b), as well as skills training in managing child misbehavior (e.g., Parent-Child Interaction Therapy [PCIT]; Eyberg 1988), may be used in tandem for helping mothers with PTSD persist with assertive parenting behaviors even when experiencing strong negative emotions. Coaching mothers with PTSD to respond more firmly to child misbehavior could increase parental effectiveness, as well as feelings of self-efficacy, and may ultimately improve long-term child outcomes.

\section{References}

Achenbach, T. M., \& Rescorla, L. A. (2000). Child behavior checklist. Burlington: ASEBA.

Amato, P. R., \& Fowler, F. (2002). Parenting practices, child adjustment, and family diversity. Journal of Marriage and Family, 64, 703-716. https://doi. org/10.1111/j.1741-3737.2002.00703.x

Ammerman, R. T., Putnam, F. W., Chard, K. M., Stevens, J., \& Van Ginkel, J. B. (2012). PTSD in depressed mothers in home visitation. Psychological Trauma Theory Research Practice and Policy, 4, 186-195. https://doi.org/10.1037/a0023062 
Arnold, E. H., \& O'Leary, S. G. (1995). The effect of child negative affect on maternal discipline behavior. Journal of Abnormal Child Psychology, 23, 585-595. https://doi. org/10.1007/BF01447663

Arnold, D. S., O'Leary, S. G., Wolff, L. S., \& Acker, M. M. (1993). The parenting scale: A measure of dysfunctional parenting in discipline situations. Psychological Assessment, 5, 137-144. https://doi.org/10.1037/1040-3590.5.2.137

Blevins, C. A., Weathers, F.W., Davis, M. T., Witte, T. K., \& Domino, J. L. (2015). The posttraumatic stress disorder checklist for DSM-5 (PCL-5): Development and initial psychometric evaluation. Journal of Traumatic Stress, 28, 489-498. https://doi. org/10.1002/jts.22059

Campbell, S. B., Shaw, D. S., \& Gilliom, M. (2000). Early externalizing behavior problems: Toddlers and preschoolers at risk for later maladjustment. Development and Psychopathology, 12, 467-488. https://doi.org/10.1017/Sog54579400003114

Casanueva, C., Martin, S. L., Runyan, D. K., Barth, R. P., \& Bradley, R. H. (2008). Quality of maternal parenting among intimate-partner violence victims involved with the child welfare system. Journal of Family Violence, 23, 413-427. https://doi. org/10.1007/s10896-008-9167-6

Charuvastra, A., \& Cloitre, M. (2008). Social bonds and posttraumatic stress disorder. Annual Review of Psychology, 59, 301-328. https://doi.org/10.1146/annurev. psych.58.110405.085650

Crandall, A., Deater-Deckard, K., \& Riley, A.W. (2015). Maternal emotion and cognitive control capacities and parenting: A conceptual framework. Developmental Review, 36, 105-126. https://doi.org/10.1016/j.dr.2015.01.004

Crandall, A., Ghazarian, S. R., Day, R. D., \& Riley, A. W. (2016). Maternal emotion regulation and adolescent behaviors: The mediating role of family functioning and parenting. Journal of Youth and Adolescence, 45, 2321-2335. https://doi. org/10.1007/s10964-015-0400-3

Creech, S. K., \& Misca, G. (2017). Parenting with PTSD: A review of research on the influence of PTSD on parent-child functioning in military and veteran families. Frontiers in Psychology, 8, 1101. https://doi.org/10.3389/fpsyg.2017.01101

Davison, K., Charles, J., Khandpur, N., \& Nelson, T. (2017). Fathers' perceived reasons for their underrepresentation in child health research and strategies to increase their involvement. Maternal \& Child Health Journal, 21, 267-274. https://doi. org/10.1007/s10995-016-2157-Z

Deater-Deckard, K., Sewell, M. D., Petrill, S. A., \& Thompson, L. A. (2010). Maternal working memory and reactive negativity in parenting. Psychological Science, 21, 7579. https://doi.org/10.1177/0956797609354073

DiLillo, D., \& Damashek, A. (2003). Parenting characteristics of women reporting a history of childhood sexual abuse. Child Maltreatment, 8, 319-333. https://doi. org/10.1177/1077559503257104

Dix, T. (1991). The affective organization of parenting: Adaptive and maladaptive processes. Psychological Bulletin, 110, 3-25. https://doi. org/10.1037/0033-2909.110.1.3

Evans, G. W. (2004). The environment of childhood poverty. American Psychologist, 59, 77-92. https://doi.org/10.1037/0003-066X.59.2.77 
Eyberg, S. (1988). Parent-child interaction therapy: Integration of traditional and behavioral concerns. Child and Family Behavior Therapy, 10, 33-46. https://doi. org/10.1300/Jo19v10no1 04

Foa, E. B., \& Rothbaum, B. O. (1998). Treating the trauma of rape: Cognitive-behavioral therapy for PTSD. New York: Guilford Press.

Foa, E. B., Ehlers, A., Clark, D.M., Tolin, D. F., \& Orsillo, S. M. (1999). The posttraumatic cognitions inventory (PTCI): Development and validation. Psychological Assessment, 11, 303-314. https://doi.org/10.1037/1040-3590.11.3.303

Gratz, K. L., \& Roemer, L. (2004).Multidimensional assessment of emotion regulation and dysregulation: Development, factor structure, and initial validation of the difficulties in emotion regulation scale. Journal of Psychopathology and Behavioral Assessment, 26, 41-54. https://doi.org/10.1023/B:JOBA.0000007455.08539.94

Gurtovenko, K., \& Katz, L. F. (2017). Posttraumatic stress, mother's emotion regulation, and parenting in survivors of intimate partner violence. Journal of Interpersonal Violence, 1-23. https://doi.org/10.1177/0886260517690874

Hayes, A. F. (2017). Introduction to mediation, moderation, and conditional process analysis: A regression-based approach (2nd ed.). New York: Guilford Publications.

Hayes, S. C., Wilson, K. G., Gifford, E. V., Follette, V.M., \& Strosahl, K. (1996). Experiential avoidance and behavioral disorders: A functional dimensional approach to diagnosis and treatment. Journal of Consulting and Clinical Psychology, 64, 1152-1168. https://doi.org/10.1037/0022-006X.64.6.1152

Hershkowitz, M., Dekel, R., Fridkin, S., \& Freedman, S. (2017). Posttraumatic stress disorder, parenting, and marital adjustment among a civilian population. Frontiers in Psychology, 8, 1655-166o. https://doi.org/10.3389/fpsyg.2017.01655

Kashdan, T. B., Uswatte, G., Steger, M. F., \& Julian, T. (2006). Fragile self-esteem and affective instability in posttraumatic stress disorder. Behaviour Research and Therapy, 44, 1609-1619. https://doi.org/10.1016/j.brat.2005.12.003

Kessler, R. C., Sonnega, A., Bromet, E., Hughes, M., \& Nelson, C. B. (1995). Posttraumatic stress disorder in the National Comorbidity Survey. Archives of General Psychiatry, 52, 1048-106o. https://doi.org/10.1001/ archpsyc.1995.03950240066012

Kotchick, B. A.,\& Forehand, R. (2002). Putting parenting in perspective: A discussion of the contextual factors that shape parenting practices. Journal of Child and Family Studies, 11, 255-269. https://doi.org/10.1023/A:1016863921662

Kuczynski, L., \& Kochanska, G. (1990). Development of children's noncompliance strategies from toddlerhood to age 5. Developmental Psychology, 26, 398-408. https://doi.org/10.1037/0012-1649.26.3.398

Leen-Feldner, E. W., Feldner, M. T., Bunaciu, L., \& Blumenthal, H. (2011). Associations between parental posttraumatic stress disorder and both offspring internalizing problems and parental aggression within the National Comorbidity SurveyReplication. Journal of Anxiety Disorders, 25, 169-175. https://doi.org/10.1016/j. janxdis.2010.08.017

Letourneau, N. L., Fedick, C. B., \& Willms, J. D. (2007). Mothering and domestic violence: A longitudinal analysis. Journal of Family Violence, 22, 649-659. https:// doi.org/10.1007/s10896-007-9099-6 
Leung, D. W., \& Slep, A. M. S. (2006). Predicting inept discipline: The role of parental depressive symptoms, anger, and attributions. Journal of Consulting and Clinical Psychology, 74, 524-534. https://doi.org/10.1037/0022-006X.74.3.524

Levendosky, A. A., Lynch, S. M., \& Graham-Bermann, S. A. (2000). Mothers' perceptions of the impact of woman abuse on their parenting. Violence Against Women, 6, 247-271. https://doi.org/10.1177/10778010022181831

Levendosky, A. A., Huth-Bocks, A. C., Shapiro, D. L., \& Semel, M. A. (2003). The impact of domestic violence on the maternal-child relationship and preschool-age children's functioning. Journal of Family Psychology, 17, 275-287.

Linehan, M. M. (1993a). Skills training manual for treating borderline personality disorder. New York: Guilford Press.

Linehan, M. M. (1993b). Cognitive-behavioral treatment of borderline personality disorder. New York: Guilford Press.

Lorber, M. F. (2007). Validity of video-mediated recall procedures for mothers' emotion and child ratings. Journal of Family Psychology, 21, 520-528. https://doi. org/10.1037/0893-3200.21.3.520

Lorber, M. F. (2012). The role of maternal emotion regulation in overreactive and lax discipline. Journal of Family Psychology, 26, 642-647. https://doi.org/10.1037/ aoo29109

Lorber, M. F., \& Slep, A. M. S. (2005). Mothers' emotion dynamics and their relations with harsh and lax discipline: Microsocial time series analyses. Journal of Clinical Child and Adolescent Psychology, 34, 559-568. https://doi.org/10.1207/ S15374424jccp3403 11

McDonagh-Coyle, A., McHugo, G. J., Friedman, M. J., Schnurr, P. P., Zayfert, C.,\& Descamps, M. (2001). Psychophysiological reactivity in female sexual abuse survivors. Journal of Traumatic Stress, 14, 667-683. https://doi. org/10.1023/A:1013081803429

Monson, C. M., Fredman, S. J., \& Dekel, R. (2010). Posttraumatic stress disorder in an interpersonal context. In J. G. Beck (Ed.), Interpersonal processes in the anxiety disorders: Implications for understanding psychopathology and treatment (pp. 179-208). Washington, DC: American Psychological Association. https://doi. org/10.1037/12084-007

Mordeno, I. G., Carpio, J. G. E., Nalipay, M. J. N., \& Saavedra, R. L. J. (2017). PTSD's underlying dimensions in typhoon Haiyan survivors: Assessing DSM-5 symptomatology- based PTSD models and their relation to posttraumatic cognition. Psychiatric Quarterly, 88, 9-23. https://doi.org/10.1007/s11126-016-9429-z

Morsbach, S. K., \& Prinz, R. J. (2006). Understanding and improving the validity of self-report of parenting. Clinical Child and Family Psychology Review, 9, 1-21. https://doi.org/10.1007/s10567-006-0001-5

Muthén, L. K. and Muthén, B. O. (1998-2017). Mplus user's guide (8th ed.). Los Angeles: Muthén \& Muthén.

Myers, H. F. (2009). Ethnicity-and socio-economic status-related stresses in context: An integrative review and conceptual model. Journal of Behavioral Medicine, 32, 9-19. https://doi.org/10.1007/s10865-008-9181-4 
Neitzel, C., \& Dopkins Stright, A. (2004). Parenting behaviours during child problem solving: The roles of child temperament, mother education and personality, and the problem- solving context. International Journal of Behavioral Development, 28, 166179. https://doi.org/10.1080/01650250344000370

Nicholson, J., Biebel, K., Williams, V. F., \& Katz-Leavy, J. (2002). Prevalence of parenthood in adults with mental illness: Implications for state and federal policy, programs, and providers. In Manderscheid, R. W., \& Henderson, M.J. (Ed.), Department of Health and Human Services, Substance Abuse and Mental Health Services Administration, Center for Mental Health Services (pp. 120-137). Rockville.

Nolten, W. E., Lindheimer, M. D., Rueckert, P., A., Oparil, \& Ehrlich, E., N. (1980). Diurnal patterns and regulation of cortisol secretion in pregnancy. The Journal of Clinical Endocrinology \& Metabolism, 51, 466-472. https://doi.org/10.1210/ jcem-51-3-466

Orsillo, S. M., Batten, S. V., Plumb, J. C., Luterek, J. A., \& Roessner, B. M. (2004). An experimental study of emotional responding in women with posttraumatic stress disorder related to interpersonal violence. Journal of Traumatic Stress, 17, 241-248. https://doi.org/10.1023/B:JOTS.0000029267.61240.94

Phares, V., Fields, S., Kamboukos, D., \& Lopez, E. (2005). Still looking for poppa. American Psychologist, 6o, 735-736. https://doi.org/10.1037/0003-066X.60.7.735

Pietrzak, R. H., Johnson, D. C., Goldstein, M. B., Malley, J. C., Rivers, A. J., Morgan, C. A., \& Southwick, S.M. (2010). Psychosocial buffers of traumatic stress, depressive symptoms, and psychosocial difficulties in veterans of operations enduring freedom and Iraqi freedom: The role of resilience, unit support, and postdeployment social support. Journal of Affective Disorders, 120, 188-192. https://doi.org/10.1016/j. jad.2009.04.015

Pinderhughes, E. E., Dodge, K. A., Bates, J. E., Pettit, G. S., \& Zelli, A. (2000). Discipline responses: Influences of parents' socioeconomic status, ethnicity, beliefs about parenting, stress, and cognitive emotional processes. Journal of Family Psychology, 14, 380-400. https://doi.org/10.1037/0893-3200.14.3.380

Samper, R. E., Taft, C. T., King, D. W., \& King, L. A. (2004). Posttraumatic stress disorder symptoms and parenting satisfaction among a national sample of male Vietnam veterans. Journal of Traumatic Stress, 17, 311-315. https://doi.org/10.1023/ B:JOTS.0000038479.30903.ed

Samuelson, K. W., Wilson, C. K., Padrón, E., Lee, S., \& Gavron, L. (2017). Maternal PTSD and children's adjustment: Parenting stress and emotional availability as proposed mediators. Journal of Clinical Psychology, 73, 693-706. https://doi. org/10.1002/jclp.22369

Santiago, C. D., Wadsworth, M. E., \& Stump, J. (2011). Socioeconomic status, neighborhood disadvantage, and poverty-related stress: Prospective effects on psychological syndromes among diverse low-income families. Journal of Economic Psychology, 32, 218-230. https://doi.org/10.1016/j.joep.2009.10.008

Schaeffer, N. C. (2000). Asking questions about threatening topics: A selective overview. In A. A. Stone, J. S. Turkkan, C. A. Bachrach, J. B. Jobe, H. S. Kurtzman, \& V. S. Cain (Eds.), The science of self-report: Implications for research and practice (pp. 105-121). Mahwah: Erlbaum. 
Shrout, P. E., \& Bolger, N. (2002). Mediation in experimental and nonexperimental studies: New procedures and recommendations. Psychological Methods, 7, 422-445. https://doi.org/10.1037/1082-989X.7.4.422

Stover, C. S., Hall, C., McMahon, T. J., \& Easton, C. J. (2012). Fathers entering substance abuse treatment: An examination of substance abuse, trauma symptoms and parenting behaviors. Journal of Substance Abuse Treatment, 43, 335-343. https:// doi.org/10.1016/j.jsat.2011.12.012

Tabachnick, B. G., \& Fidell, L. S. (1996). Using multivariate statistics (3rd ed.). New York: HarperCollins.

Thoemmes, F., MacKinnon, D. P., \& Reiser, M. R. (2010). Power analysis for complex mediational designs using Monte Carlo methods. Structural Equation Modeling, 17, 510-534. https://doi.org/10.1080/10705511.2010.489379

Tutus, D., \& Goldbeck, L. (2016). Posttraumatic symptoms and cognitions in parents of children and adolescents with PTSD. European Child \& Adolescent Psychiatry, 25, 997-1005. https://doi.org/10.1007/s00787-016-0821-X

van Ee, E., Kleber, R. J., \& Mooren, T. (2012). War trauma lingers on: Associations between maternal posttraumatic stress disorder, parent-child interaction, and child development. Infant Mental Health Journal, 33, 459-468. https://doi.org/10.1002/ imhj. 21324

van Ee, E., Kleber, R. J., \& Jongmans, M. J. (2015). Relational patterns between caregivers with PTSD and their nonexposed children. Trauma, Violence \& Abuse, 17, 186-203. https://doi.org/10.1177/1524838015584355

Veazey, C. H., Blanchard, E. B., Hickling, E. J., \& Buckley, T. C. (2004). Physiological responsiveness of motor vehicle accident survivors with chronic posttraumatic stress disorder. Applied Psychophysiology and Biofeedback, 29, 51-62. https://doi. org/10.1023/B:APBI.0000017863.35714.a1

Vujanovic, A. A., Bonn-Miller, M. O., Potter, C. M., Marshall, E. C., \& Zvolensky, M. J. (2011). An evaluation of the relation between distress tolerance and posttraumatic stress within a trauma-exposed sample. Journal of Psychopathology and Behavioral Assessment, 33, 129-135. https://doi.org/10.1007/s10862-010-9209-2

Weathers, F. W., Blake, D. D., Schnurr, P. P., Kaloupek, D. G., Marx, B. P., \& Keane, T. M. (2013a). The life events checklist for DSM-5 (LEC-5). Instrument available from the National Center for PTSD at www.ptsd.va.gov

Weathers, F. W., Blake, D. D., Schnurr, P. P., Kaloupek, D. G., Marx, B. P., \& Keane, T. M. (2013b). The clinician-administered PTSD scale for DSM-5 (CAPS-5). Interview available from the National Center for PTSD at www.ptsd.va.gov

Weathers, F. W., Bovin, M. J., Lee, D. J., Sloan, D. M., Schnurr, P. P., Kaloupek, D. G., ... \& Marx, B. P. (2017). The clinician-administered PTSD scale for DSM-5 (CAPS-5): Development and initial psychometric evaluation in military veterans. Psychological Assessment, 30, 383-395. https://doi.org/10.1037/pasoooo486

Wisco, B. E., Marx, B. P., \& Keane, T. M. (2012). Screening, diagnosis, and treatment of post- traumatic stress disorder. Military Medicine, 117, 7-13. https://doi. org/10.7205/MILMED-D-12-00111

Zalewski, M., Lewis, J. K., \& Martin, C. G. (2018). Identifying novel applications of dialectical behavior therapy: Considering emotion regulation and parenting. Current Opinion in Psychology, 21, 122-126. https://doi.org/10.1016/j. copsyc. 2018.02 